\title{
Evidence of Unilateral Metastatic Pulmonary Calcification with a Prolonged Fever and Arthralgia Caused by Acute Lymphoblastic Leukemia in a Chronic Dialysis Patient
}

\author{
Takeshi Saraya ${ }^{1}$, Mitsuru Sada ${ }^{1}$, Kosuke Ohkuma ${ }^{1}$, Sho Sakuma ${ }^{1}$, Naoki Tsujimoto ${ }^{1}$, \\ Shigehiko Yoshida ${ }^{2}$, Masachika Fujiwara ${ }^{3}$, Yayoi Tsukahara ${ }^{4}$, Daisuke Kurai ${ }^{1}$, \\ Haruyuki Ishii ${ }^{1}$, Hajime Takizawa ${ }^{1}$ and Hajime Goto ${ }^{1}$
}

\begin{abstract}
A 55-year-old man was transferred to our hospital with unilateral lung lesions, a persistent fever and vague chest pain with arthralgia lasting for three months. He had been treated for end-stage renal disease with hemodialysis for 15 years and had a medical history of recurrent subcutaneous calciphylaxis due to secondary hyperparathyroidism. Transbronchial biopsied specimens demonstrated metastatic pulmonary calcification, and a bone marrow biopsy showed Philadelphia chromosome-positive acute lymphoblastic leukemia. Although metastatic calcification often lacks specific symptoms, the lungs is a primary site for deposition. This is the first report of unilateral metastatic pulmonary calcification associated with secondary hyperparathyroidism.
\end{abstract}

Key words: end-stage renal disease, metastatic pulmonary calcification, secondary hyperparathyroidism, acute lymphoblastic leukemia

(Intern Med 54: 63-67, 2015)

(DOI: 10.2169/internalmedicine.54.2840)

\section{Introduction}

Metastatic pulmonary calcification is classified as visceral, non-visceral or a combination of both within the same patient $(1,2)$. This condition should be considered in all patients with end-stage renal disease with secondary hyperparathyroidism and an elevated calcium-phosphate product level, particularly those with bilateral metastatic pulmonary calcification (3). We herein present the first evidence for unilateral metastatic pulmonary calcification in a chronic dialysis patient who was incidentally diagnosed with acute lymphoblastic leukemia.

\section{Case Report}

A 55-year-old man was transferred to our hospital due to abnormal lung lesions, a persistent fever and vague chest pain with arthralgia lasting for three months. The patient had been treated with hemodialysis for focal glomerular sclerosis resulting from end-stage renal disease (ESRD) for 15 years and had a history of recurrent subcutaneous calciphylaxis over the last three years. Seven years prior to visiting our hospital, massive subcutaneous calcification was noted (Fig. 1); the lesions were successfully resected and diagnosed as reflecting massive calcification with granulomatous fibrous tissue. However, a left back subcutaneous mass recurred in association with methicillin-resistant Staphylococcus aureus infection, and the tumor was successfully resected and drained three years prior to admission. Two years prior to admission, the patient had undergone left parathyroidectomy to treat secondary hyperparathyroidism associated with ESRD, and implantation of parathyroid tissue in the right forearm muscle was performed to maintain a resid-

${ }^{1}$ Department of Respiratory Medicine, Kyorin University School of Medicine, Japan, ${ }^{2}$ Inokashira Clinic, Japan, ${ }^{3}$ Department of Pathology, Kyorin University School of Medicine, Japan and ${ }^{4}$ Department of Radiology, Kyorin University School of Medicine, Japan

Received for publication March 10, 2014; Accepted for publication May 14, 2014

Correspondence to Dr. Takeshi Saraya, sara@yd5.so-net.ne.jp 

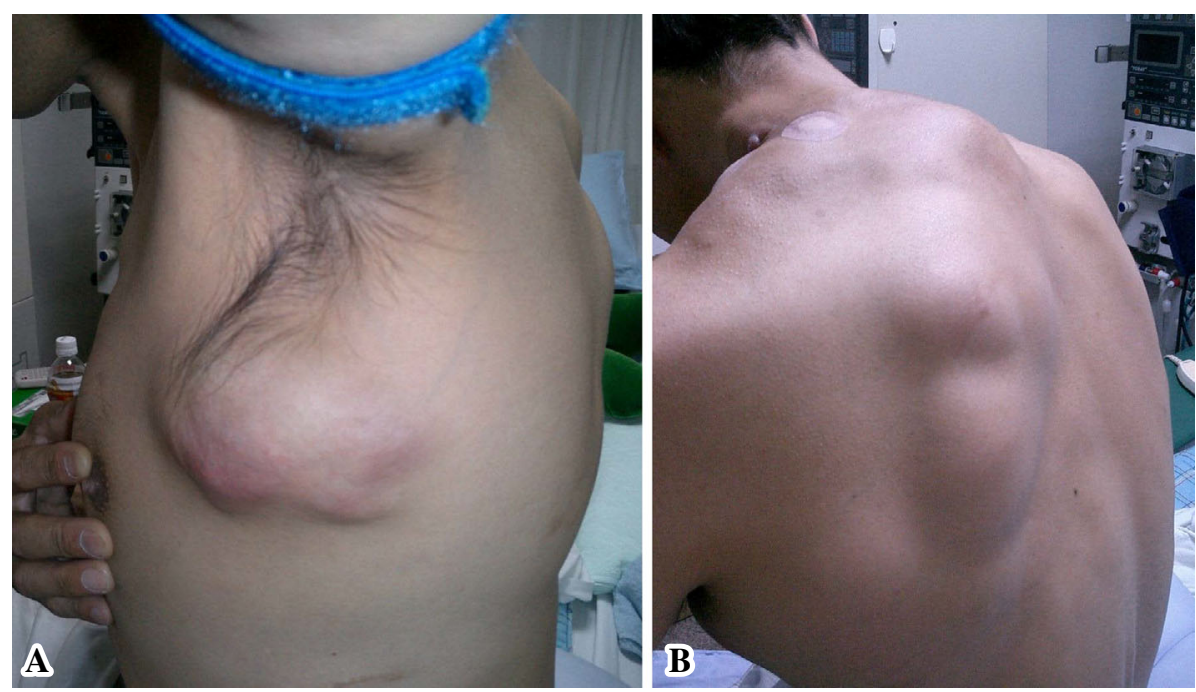

Figure 1. Areas of massive subcutaneous calcification, so-called calciphylaxis, were noted in the left axillar region (A) and on the patient's left back (B).
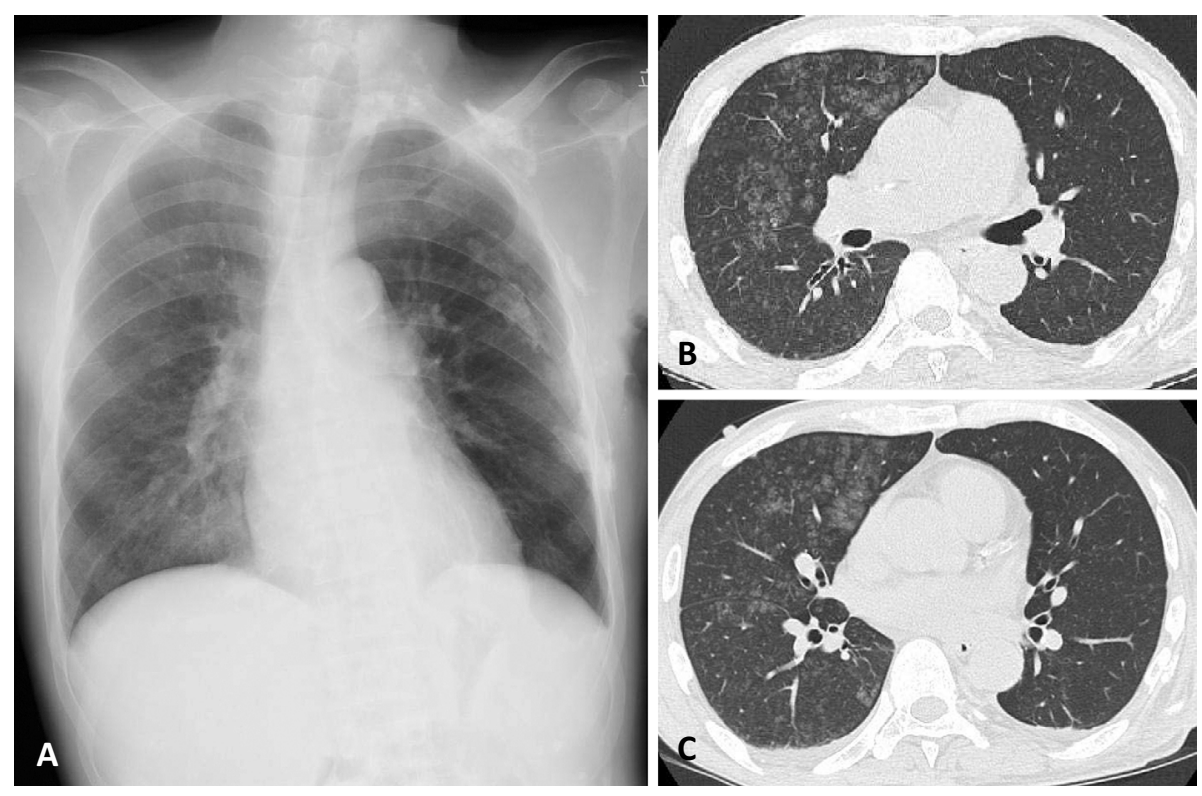

Figure 2. A chest X-ray (A) demonstrated faint infiltration involving the entire right lung, with calcification in the left lung. Thoracic computed tomography showed fluffy and poorly defined nodules scattered throughout the right lung field only, predominantly in the upper to middle lobes (B, C).

ual parathyroid function. He was subsequently treated with various antibiotics for suspected pneumonia at a local hospital; however, the remittent fever and chest pain persisted.

On admission (day 1), the patient's general condition was good, and his vital signs were normal, with the exception of a high temperature $\left(38.2^{\circ} \mathrm{C}\right)$ and tachycardia $(104 / \mathrm{min})$. No findings related to arthralgia were evident. He was an exsmoker with a four pack-year history and reported drinking one bottle of beer daily. He denied any dust exposure or illicit drug use, although he admitted to poor adherence to his prescribed drug regimen, including sevelamer hydrochloride (500 mg/day) and calcium carbonate $(1,000 \mathrm{mg} /$ day) for secondary hyperparathyroidism due to ESRD. A chest X-ray (Fig. 2A) demonstrated faint infiltration involving the whole right lung with calcification in the left lung. The areas of calcification in the left lung on the chest X-ray were not located in the lung parenchyma, but rather in the left posterior subcutaneous tissue (Fig. 1A). Thoracic computed tomography (CT) showed fluffy and poorly defined nodules scattered throughout the right lung field only, predominantly in the upper to middle lobes (Fig. 2B, C), with no apparent thickening of the interlobular septa. A laboratory examination showed mild anemia $(9.5 \mathrm{~g} / \mathrm{dL})$, hypoalbuminemia $(2.1$ $\mathrm{g} / \mathrm{dL})$ and hypercalcemia $(11.5 \mathrm{mg} / \mathrm{dL})$, with mild elevation of the lactase dehydrogenase (236 IU/L) and glutamate oxaloacetate transaminase (40 IU/L) levels and marked elevation of the C-reactive protein $(28.3 \mathrm{mg} / \mathrm{dL})$, blood urea nitrogen $(73.5 \mathrm{mg} / \mathrm{dL})$, creatinine $(10.4 \mathrm{mg} / \mathrm{dL})$ and phosphate 


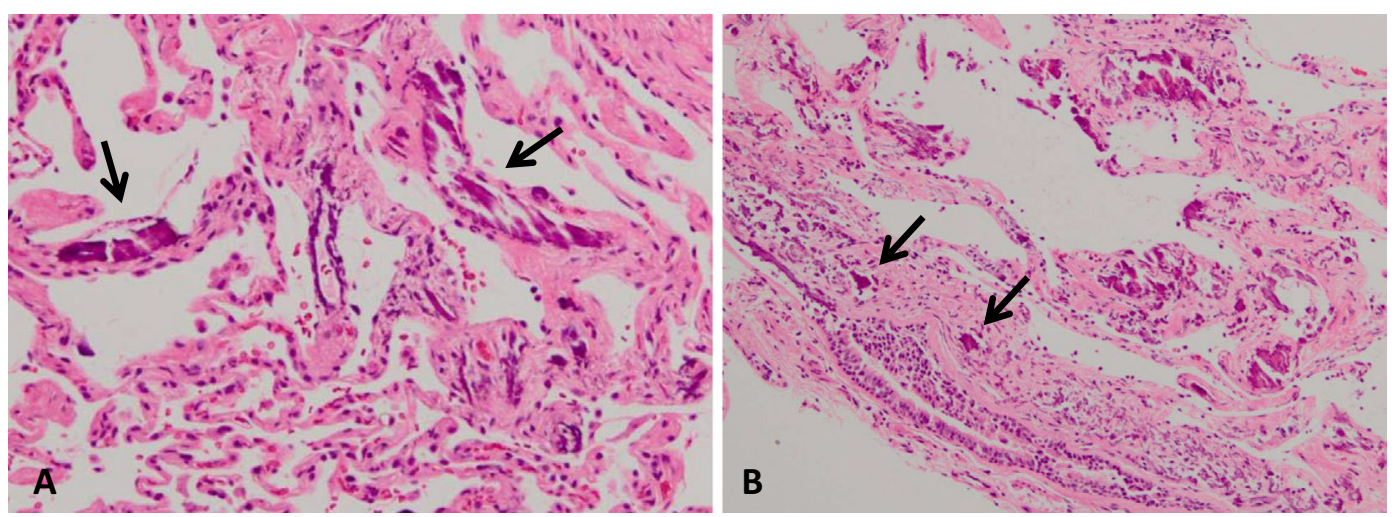

Figure 3. On Hematoxylin and Eosin staining, the biopsied specimens obtained from the left B4a segment showed thickening of the alveolar walls and interstitial spaces (A, arrows) as well as bronchial walls (B, arrows), with calcium deposition.
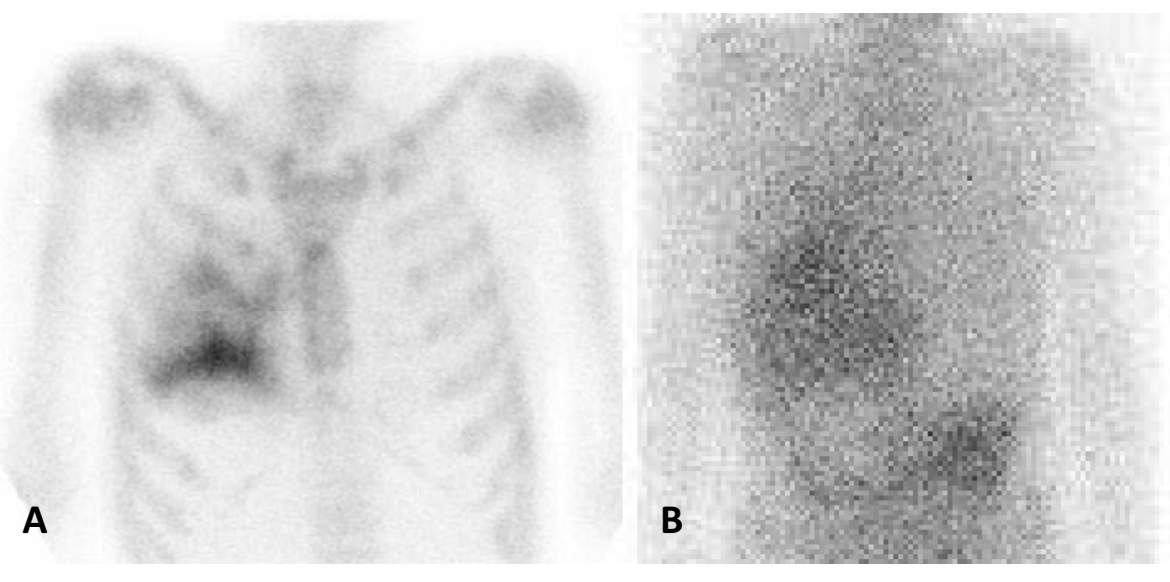

Figure 4. Bone scintigraphy (A) showed a hot spot in the middle to lower lungs, corresponding to the hot areas on gallium scintigraphy $(B)$.

$(8.7 \mathrm{mg} / \mathrm{dL})$ levels, in association with an intact parathyroid hormone (iPTH: 763 pg/mL) level, suggesting secondary hyperparathyroidism due to ESRD. The number of white blood cells and platelets was normal $(4,600 / \mu \mathrm{L})$, with no atypical or blast cells, although moderate nephrogenic anemia $(9.5 \mathrm{~g} /$ dL) was noted. The serum values of Krebs von den Lungen$6(136 \mathrm{U} / \mathrm{mL})$, surfactant protein $\mathrm{D}(\leq 17.2 \mathrm{ng} / \mathrm{mL})$ and $\beta$-Dglucan were normal, and antibodies for the human immunodeficiency virus and human $\mathrm{T}$ cell leukemia virus were negative. Repeated blood cultures were also negative, and cardiac echocardiography showed no vegetation. A pulmonary function test demonstrated a normal vital capacity of 3.57 L (\%VC: $92.3 \%$ ) and forced expiratory volume of 2.53 L (\%FEV1.0: 70.3\%); however, both the diffusing capacity of the lung for carbon monoxide (DLCO: 55\%) and DLCO/ alveolar volume $(54 \%)$ were decreased.

Although the patient had no respiratory symptoms, based on the suspicion of a lung disease, a transbronchial lung biopsy (TBLB) and bronchoalveolar lavage (BAL) were performed. On hematoxylin and eosin staining, the biopsied specimens obtained from the left B4a segment showed thickening of the alveolar walls and interstitial spaces (Fig. 3A, arrows) as well as the bronchial walls (Fig. 3B, arrows), with calcium deposition, a potential cause of the decreased DLCO value. A BAL fluid analysis of the left B5 a segment showed only mild elevation of the total cell count $\left(1.2 \times 10^{5} / \mathrm{mL}\right)$ with a normal cell differential (macrophages: 96\%, lymphocytes: $4 \%$, neutrophils: $0 \%$ ), and the ratio of CD4 to CD8 lymphocytes was mildly elevated (2.32). No malignant cells were noted, and cultures and smears for fungi and bacteria, including acid-fast strains, were negative. Both bone (Fig. 4A) and gallium (Fig. 4B) scintigraphy showed a hot spot in the middle to lower lungs, which corresponded to the areas of lung involvement. Around that time, we observed the metastatic pulmonary calcification (MPC) to be more faint in the same area on high-resolution (HR) CT performed two years previously. Therefore, the patient was tentatively diagnosed with MPC associated with ESRD, possibly due to secondary hyperparathyroidism; however, no other sources of fever of unknown origin (FUO) were noted.

However, on day 21, blast cells were detected in the pe- 
ripheral blood, and bone marrow biopsy specimens showed abundant lymphoblastic cells positive for CD79a and terminal deoxynucleotidyl transferase (TdT) but negative for myeloperoxidase (figure not shown). The patient was finally diagnosed as having Philadelphia chromosome-positive acute lymphoblastic leukemia (ALL) with MPC associated with secondary hyperparathyroidism. To control the hypercalcemia, the parathyroid tissue in the right forearm muscle was resected on day 31 . On the same day, intravenous prednisolone therapy $(60 \mathrm{mg} /$ day) and treatment with oral dasatinib hydrate $(100 \mathrm{mg} /$ day $)$ were initiated for the ALL. Surprisingly, the patient's chief complaints, including FUO, arthralgia and vague chest pain, disappeared within the first six days after treatment, accompanied by a dramatic resolution of the hypercalcemia and hyperphosphatemia, although MPC continued to be noted on HRCT performed two months later. Four months after the initiation of treatment, he remains in good health, without relapse of his symptoms.

\section{Discussion}

The etiology of metastatic calcification can be divided into subtypes, including visceral (lungs, stomach, kidneys, heart and muscles), non-visceral (calciphylaxis), which primarily affects the small to medium arteries of the dermis and subcutaneous tissue, and a combination of both types within the same patient $(1,2)$. Although abnormal pulmonary and cardiac calcification has been reported at autopsy in $20-80 \%$ of patients with $\operatorname{ESRD}(4,5)$, such calcification is rarely identified on chest radiographs. Against this background, the present case was categorized as a combination of both types of calcification, and lung involvement was even noted on a chest X-ray. The upper pulmonary lobes are more frequently involved in patients with MPC due to the higher local blood $\mathrm{pH}$ and lower partial pressure of arterial oxygen $\left(\mathrm{PaCO}_{2}\right)$, resulting in a local alkaline environment $(6,7)$. Pathologically, MPC can be found in the pulmonary interstitium or arterioles and bronchial walls $(5,8)$; however, the predominant sites of calcium deposition are the alveolar septa and, to a lesser extent, the pulmonary arteries or bronchioles, which accounts for the lack of interlobular septal thickening (4). From this point of view, the present case involved characteristic radiological (fluffy nodules without thickening of the interlobular septa) and pathological findings of MPC, although the patient exhibited atypical aspects for MPC, such as unilateral lung involvement, a prolonged fever with arthralgia and vague chest pain. However, Cotellese et al. (9) reported that surgically treated patients with secondary hyperparathyroidism due to ESRD display diverse symptoms, such as persistent hypercalcemia, osteodystrophy with bone fractures, joint pain, itching and ectopic calcification, as observed in the present case. On the other hand, FUO due to secondary hyperparathyroidism has not been reported, except for one case of primary hyperparathyroidism (10). Regarding unilateral involvement of MPC, the current patient preferred right lateral positioning during maintenance hemodialysis and/or sleeping. This position would result in a relative increase in blood flow to the right lung, which would make the patient vulnerable to the development of calcification, as described above.

The mechanisms of gallium uptake in MPC are not precisely known (11), although the lung uptake of Ga-67 in the absence of infection, neoplasms, acute respiratory distress syndrome or pleural effusion suggests the possibility of MPC (12), as noted in the present case. The calcium complexes present in sites of visceral calcification are composed of calcium, phosphate and magnesium, whereas those in the subcutaneous tissue (non-visceral calcification, so-called calciphylaxis) do not contain magnesium and are less stable (2). The difference in composition between sites of calcification may explain the negative results in the left posterior subcutaneous area of calcification on both bone and gallium scintigraphy in the present case.

The accumulation of blast cells in the bone results in bone and joint pain (13). In this clinical context, the present patient's FUO, arthralgia and vague chest pain are considered to be primarily caused by the ALL, while the hypercalcemia and hyperphosphatemia can be attributed to either the ALL (14) or secondary hyperparathyroidism due to ESRD (15) as well as oral loading of calcium carbonate.

The present case involved a unique clinical presentation with unilateral lung lesions of MPC and non-specific clinical findings associated with secondary hyperparathyroidism and/or ALL.

This is the first report of unilateral metastatic pulmonary calcification associated with secondary hyperparathyroidism complicated with acute lymphoblastic leukemia. The potential for metastatic pulmonary calcification should be considered, even in cases of unilateral pulmonary involvement.

The authors state that they have no Conflict of Interest (COI).

\section{References}

1. Cadavid JC, DiVietro ML, Torres EA, Fumo P, Eiger G. Warfarininduced pulmonary metastatic calcification and calciphylaxis in a patient with end-stage renal disease. Chest 139: 1503-1506, 2011.

2. Ullmer E, Borer H, Sandoz P, Mayr M, Dalquen P, Soler M. Diffuse pulmonary nodular infiltrates in a renal transplant recipient. Metastatic pulmonary calcification. Chest 120: 1394-1398, 2001.

3. Dhanjal TS, Babu SB, Beevers G, Ferner RE. Calciphylaxis associated with widespread pulmonary calcification. BMJ Case Rep 2009: 2009.

4. Hartman TE, Muller NL, Primack SL, et al. Metastatic pulmonary calcification in patients with hypercalcemia: findings on chest radiographs and CT scans. AJR Am J Roentgenol 162: 799-802, 1994.

5. Conger JD, Hammond WS, Alfrey AC, Contiguglia SR, Stanford RE, Huffer WE. Pulmonary calcification in chronic dialysis patients. Clinical and pathologic studies. Ann Intern Med 83: 330336, 1975.

6. National Kidney F. K/DOQI clinical practice guidelines for bone metabolism and disease in chronic kidney disease. Am J Kidney Dis 42: S1-S201, 2003.

7. Lingam RK, Teh J, Sharma A, Friedman E. Case report. Metas- 
tatic pulmonary calcification in renal failure: a new HRCT pattern. Br J Radiol 75: 74-77, 2002.

8. Madhusudhan KS, Shad PS, Sharma S, Goel A, Mahajan H. Metastatic pulmonary calcification in chronic renal failure. Int Urol Nephrol 44: 1285-1287, 2012.

9. Cotellese R, Mariano F, Costantini R, Francomano F, Napolitano L. Indications and efficacy of parathyroidectomy in the treatment of secondary hyperparathyroidism in patients with chronic renal failure: our experience. Chir Ital 56: 47-53, 2004.

10. Ricci J, Vlasschaert J, Salit IE. Prolonged fever associated with primary hyperparathyroidism. Can Med Assoc J 131: 459-460, 1984.

11. Auerbach JM, Ho J. Gallium-67 uptake in the lung associated with metastatic calcification. AJR Am J Roentgenol 136: 605-607, 1981.
12. Davidson RM, Dhekne RD, Moore WH, Butler DB. Metastatic calcification in a patient with malignant parathyroid carcinoma. Correlation of clinical, surgical, radiographic, and scintigraphic findings. Clin Nucl Med 15: 692-696, 1990.

13. Redaelli A, Laskin BL, Stephens JM, Botteman MF, Pashos CL. A systematic literature review of the clinical and epidemiological burden of acute lymphoblastic leukaemia (ALL). Eur J Cancer Care (Engl) 14: 53-62, 2005.

14. Fukasawa H, Kato A, Fujigaki Y, Yonemura K, Furuya R, Hishida A. Hypercalcemia in a patient with B-cell acute lymphoblastic leukemia: a role of proinflammatory cytokine. Am J Med Sci 322: 109-112, 2001.

15. Young EW, Albert JM, Satayathum S, et al. Predictors and consequences of altered mineral metabolism: the Dialysis Outcomes and Practice Patterns Study. Kidney Int 67: 1179-1187, 2005.

(C) 2015 The Japanese Society of Internal Medicine http://www.naika.or.jp/imonline/index.html 